LAWRENCE LIVERMORE NATIONAL LABORATORY

\title{
Characterization of the \\ Series 1000 Camera System
}

J.R. Kimbrough, J.D. Moody, P.M. Bell, O.L. Landen

April 9, 2004

$15^{\text {th }}$ Topical Conference on High-Temperature Plasma Diagnostics, San Diego, CA, April 19-22, 2004 
This document was prepared as an account of work sponsored by an agency of the United States Government. Neither the United States Government nor the University of California nor any of their employees, makes any warranty, express or implied, or assumes any legal liability or responsibility for the accuracy, completeness, or usefulness of any information, apparatus, product, or process disclosed, or represents that its use would not infringe privately owned rights. Reference herein to any specific commercial product, process, or service by trade name, trademark, manufacturer, or otherwise, does not necessarily constitute or imply its endorsement, recommendation, or favoring by the United States Government or the University of California. The views and opinions of authors expressed herein do not necessarily state or reflect those of the United States Government or the University of California, and shall not be used for advertising or product endorsement purposes. 


\title{
Characterization of the Series 1000 Camera System
}

\author{
J. R. Kimbrough, J. D. Moody, P. M. Bell, O. L. Landen \\ Lawrence Livermore National Laboratory, Livermore, California 94551-0808
}

\begin{abstract}
The National Ignition Facility requires a compact network addressable scientific grade CCD camera for use in diagnostics ranging from streak cameras to gated x-ray imaging cameras. Due to the limited space inside the diagnostic, an analog and digital input/output option in the camera controller permits control of both the camera and the diagnostic by a single Ethernet link. The system consists of a Spectral Instruments Series 1000 camera, a PC104+ controller, and power supply. The $4 \mathrm{k}$ by $4 \mathrm{k}$ CCD camera has a dynamic range of $70 \mathrm{~dB}$ with less than 14 electron read noise at a $1 \mathrm{MHz}$ readout rate. The PC104+ controller includes 16 analog inputs, 4 analog outputs and 16 digital input/output lines for interfacing to diagnostic instrumentation. A description of the system and performance characterization is reported.
\end{abstract}

\section{INTRODUCTION}

In the mid 1990s Lawrence Livermore National Laboratory (LLNL) scientists began replacing film cameras with high resolution CCD cameras for use in Nova facility at LLNL and at the Laboratory for Laser Energetics. ${ }^{1,2,3}$ The National Ignition Facility (NIF) requires a compact scientific grade camera and a diagnostic controller that can be used with various diagnostics. A primary physical requirement is to fit inside the standard air-box cross section of 13.3 by $13.0 \mathrm{~cm}$. The camera would be a replacement for Spectral Instruments Series 800 
cameras. The Series 1000 was configured based on experience with the Spectral Instruments Series $800 .^{4}$

Additional requirements were that it must be based on a bus, form factor, and standard operating system with broad industrial base and be compatible with "Requirements and Recommendations for Target Diagnostic Development." These features provide the flexibility to change boards to meet diagnostic needs and simplify software development and maintenance. The PC104+ architecture was selected. ${ }^{6}$ This controller is in the design of the NIF Gated X-ray Detector and NIF Dante diagnostics. ${ }^{7,8}$

\section{DESCRIPTION}

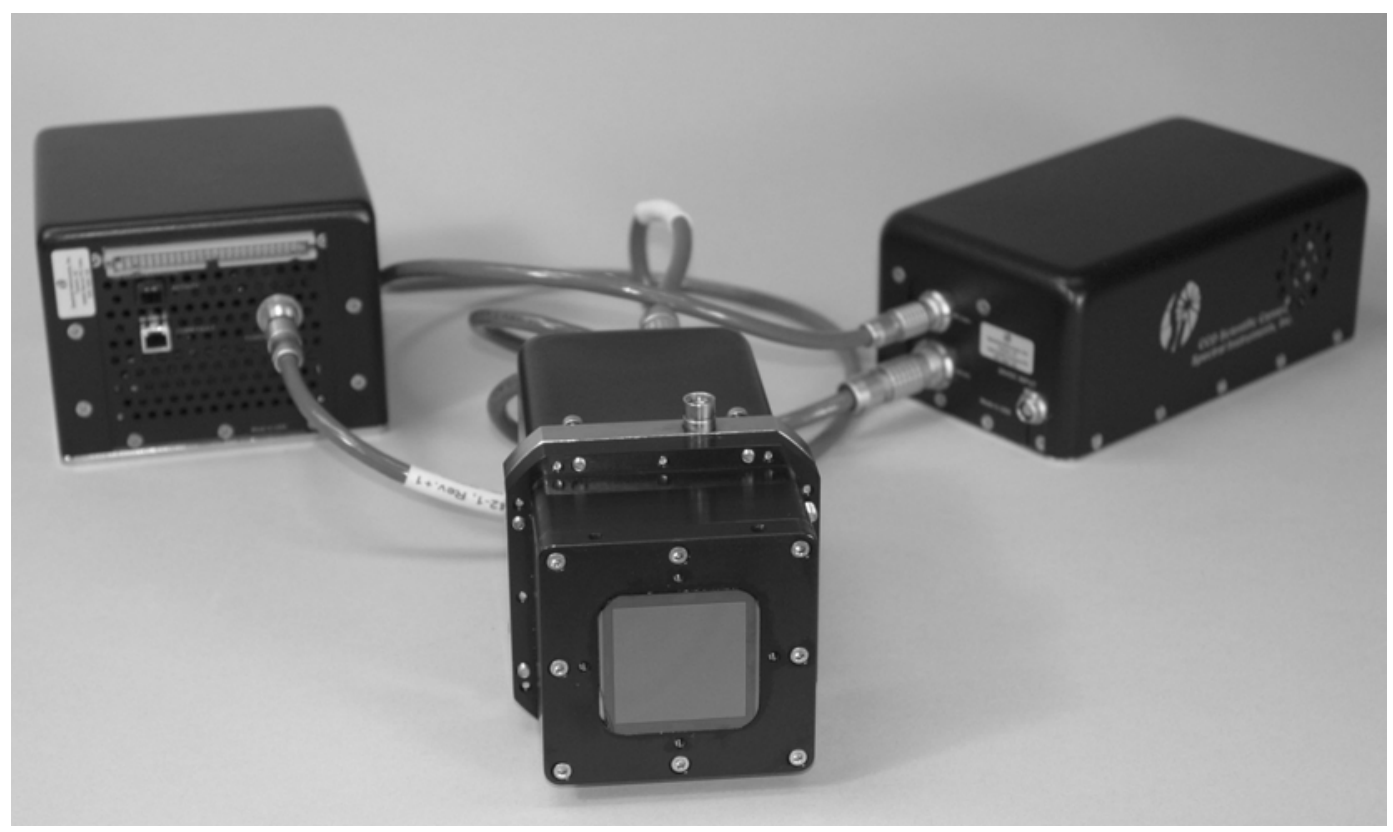

FIG. 1. Spectral Instruments Series 1000 camera system.

The three major subsystems are the CCD camera, the controller, and power supply as shown in Fig. 1. The water cooled camera features are: fully encloses the CCD in the vacuum housing, has $1 / 4$-inch cooling lines, supports NIF's electrical and optical triggers, and has both 
PCI and PC104+ interface boards. The increase from $1 / 8$ to $1 / 4$-inch cooling lines and the elimination of several right angle turns in the camera increased the water flow from $750 \mathrm{ml} / \mathrm{min}$ for the Spectral Instruments Series 800 to $1550 \mathrm{ml} / \mathrm{min}$ using a PolyScience chiller rated at $5 \mathrm{psi}$. The CCD is a Kodak 16801E CCD with Incom $33 \mathrm{~mm}$ long fiber optic bundle with $6 \mu \mathrm{m}$ diameter fiber attached to the CCD. The CCD is 4096 by 4096 with $9 \mu \mathrm{m}$ square pixels based on a Single Indium Tin Oxide (SITO) design, which increases light transmission to the active area of the pixel. The chip size of 36.8 by $36.8 \mathrm{~mm}$ makes it equivalent in size to the original film based diagnostics. The camera is $9.1 \mathrm{~cm}$ high, $9.1 \mathrm{~cm}$ wide, and $15.6 \mathrm{~cm}$ long. This is $5 \mathrm{~cm}$ less in length and $2 \mathrm{~cm}$ less in diameter than Series 800 .

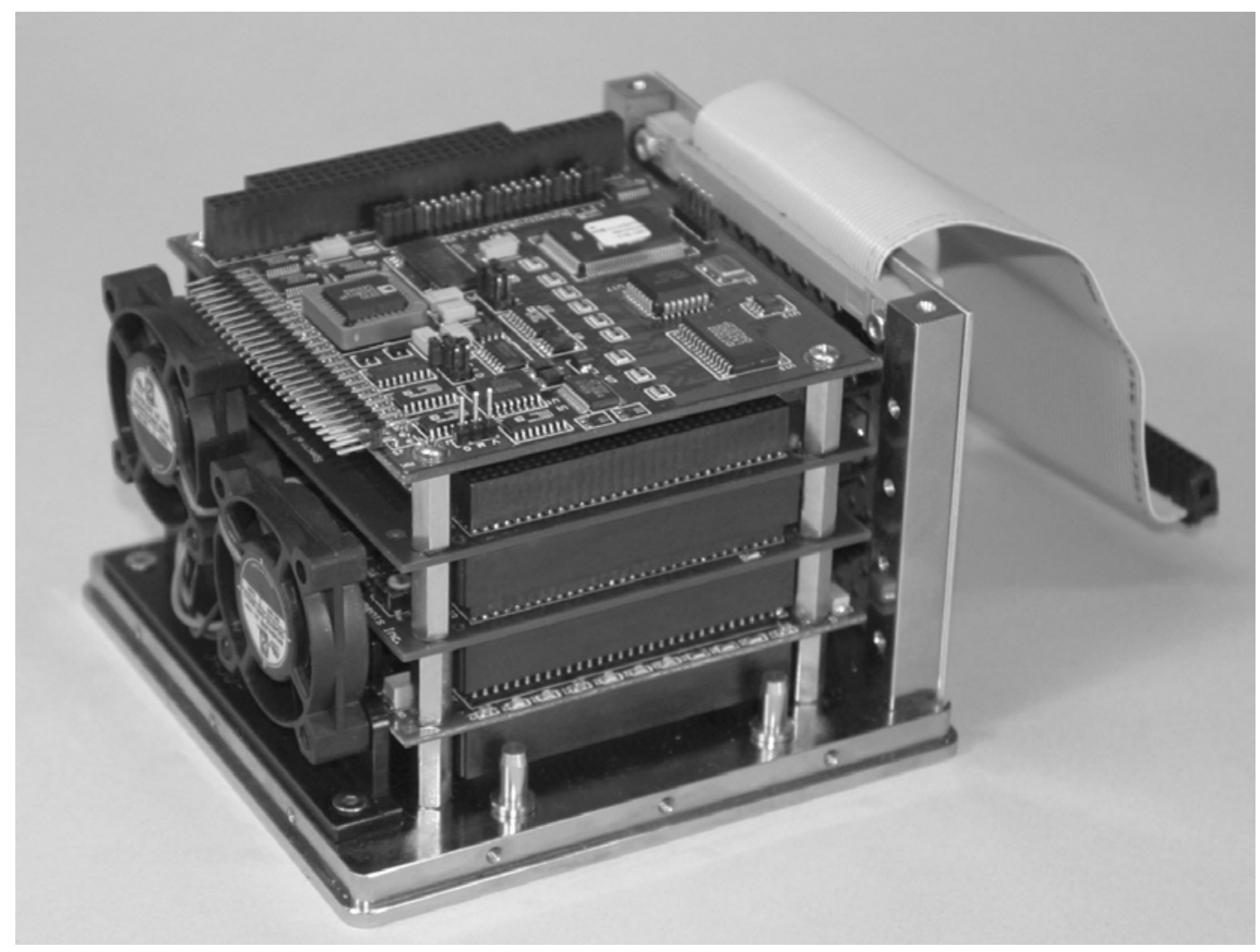

FIG. 2. PC104+ Module showing ADC board. 
The controller is based on PC104+ architecture and form factor shown in Fig. 2. The controller consists of the processor board, with both an ISA and PCI bus, an analog input/output board, camera controller, and fiber optic Ethernet board. The processor board is a WinSystems PPM-TX-266-ST board. The board contains: 1) a 266 MHZ Intel Pentium MXCPU with 256 MB of memory, 2) watch dog timer, 3) 10/100 Mbps Ethernet port, 4) two interrupt controllers, 5) seven DMA channels, 6) three 16-bit counters, and 7) four RS232 ports.

The analog/digital I/O board is a Diamond MM-16-AT. The board has 16 analog inputs with \pm 10 volt range, 16 -bit resolution, and $100 \mathrm{KHz}$ sampling rate. There are four analog outputs with 12-bit resolution and a +10 volt range. The 16 digital I/O lines can be configured as either input or output. A 50 pin ribbon connector allows access to the $\mathrm{I} / \mathrm{O}$.

The Spectral Instruments boards are the camera interface and fiber optic Ethernet boards. The interface board communicates to the camera using a giga Hertz MT-RJ fiber optic interface. This board also monitors the current in the two cooling fans and a pair of temperature monitors. The other board converts the 100 base-T Ethernet connection on the processor board to a 100 base-FX fiber optic Ethernet. The controller dimensions are $9.2 \mathrm{~cm}$ high, $12.1 \mathrm{~cm}$ wide, and 12.0 cm long. Fig. 3 shows how the CCD camera and PC104+ controller are used in a diagnostic. Spectral Instruments power supply has +28 VDC input, which is standard for NIF diagnostics. The power supply provides $+5 \mathrm{VDC},+15 \mathrm{VDC}, \pm 13 \mathrm{VDC},+24 \mathrm{VDC}$ to the camera, and $+5 \mathrm{VDC},+12 \mathrm{VDC}$ to the controller. The power supply is $7.2 \mathrm{~cm} \mathrm{high,} 10.1 \mathrm{~cm}$ wide, and $17 \mathrm{~cm}$ long.

The operating system is Windows XP Embedded with $\mathrm{C}$ and $\mathrm{C}++$ drivers and libraries for the camera and I/O board. JAVA is the desired application development language. The 
operating system is bootable from the network as a diskless system or can operate stand alone from a disk on chip.

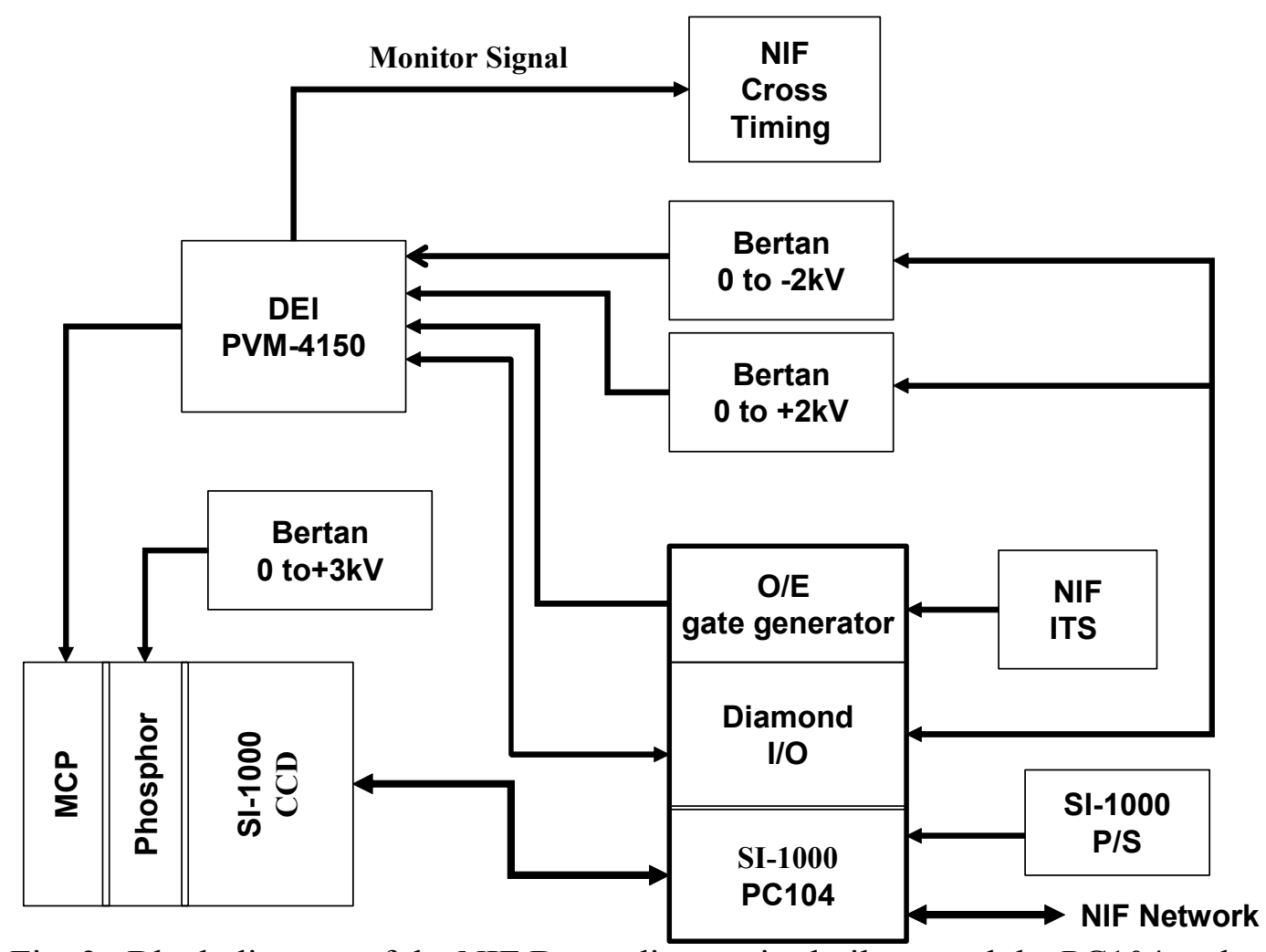

Fig. 3. Block diagram of the NIF Dante diagnostics built around the PC104 and camera.

\section{TEST SETUP}

The light source is a Gamma Scientific RS-5 Digital Light Source System with a calibrated DC output. The RS-5 system has $460 \mathrm{~nm}$ and $530 \mathrm{~nm}$ heads. The RS-5 head was mounted to the FFI (Flat-Field Illuminator by Gamma Scientific) and a shutter installed in the FFI. A 2.3 ND filter was mounted after the shutter followed by an Edmund Scientific diffuser at the output of the FFI. The camera's fiber optic faceplate made direct contact with the fiber optic faceplate of the illumination system. The camera acquired an image for 2 seconds, with the shutter open for $1 / 2$ second, starting $200 \mathrm{~ms}$ after the start. 


\section{TEST PROCEDURE}

The camera remained at $-15^{\circ} \mathrm{C}$ for a minimum of 20 minutes prior to taking data. Tests were done at both $690 \mathrm{kHz}$ and $1000 \mathrm{kHz}$ readout rates. The data acquisition procedure was: 1) With illumination system off-acquire and save two bias images, 2) Turn RS-5 Illumination system on to $\geq 300 \mu \mathrm{W} / \mathrm{cm}^{2}$ with the $530 \mathrm{~nm}$ head. Acquire and save 2 flat-field images, 3) Repeat step 2 for $200,100,70,50,20,10$, and $\left.5 \mu \mathrm{W} / \mathrm{cm}^{2}, 4\right)$ Repeat the 50 illumination value to verify data repeatability, 5) Repeat bias image with illumination off for verification of system stability, 6) Adjust camera software to the second readout rate and repeat steps 1 through 5,7) Finally replace the RS-5 $530 \mathrm{~nm}$ head with the $460 \mathrm{~nm}$ head, 8) Repeat steps 1 through 6 with the $460 \mathrm{~nm}$ head.

After the camera tests a UDT PL8C silicon photodiode replaced the camera at the output end of the illumination system. The RS-5 was adjusted to the various illumination levels for each head and current readings from the photodiode were recorded.

The final step was to measure the camera resolution. To determine resolution, a 1951 USAF Resolution Target was projected onto the fiber optic faceplate of the camera by an Optoliner.

\section{ANALYSIS}

The first step was to determine the photometric properties of the test setup. Equation 1 shows the calculation photons $/ \mathrm{s}-\mathrm{m}^{2}$ for a given wavelength in $\mathrm{nm}$. $\mathrm{I}_{\mathrm{d}}$ is the photodiode current (A), $A_{d}$ is the is the detector area $\left(\mathrm{m}^{2}\right), R_{d}$ is the detector responsivity (A/W), $\lambda$ is the illumination wavelength (in m), $h$ is Planck's constant, $6.626 \times 10^{-34} \mathrm{Js}$, and $c$ is the speed of 
light, $2.998 \times 10^{8} \mathrm{~m} / \mathrm{s}$. At $460 \mathrm{~nm}$ there are $2.32 \times 10^{18}$ photons $/ \mathrm{J}$ and at $530 \mathrm{~nm}$ there are 2.67 $\mathrm{x} 10^{18}$ photons $/ \mathrm{J}$.

$$
\text { Photons } / \mathrm{s}-\mathrm{m}^{2}=\frac{I_{d}}{\left(A_{d} * R_{d}\right) *\left(\frac{h c}{\lambda}\right)}
$$

The values from equation 1 multiplied by the 0.5 second exposure time and the $81 \mu \mathrm{m}^{2}$ area of the pixel of the camera under test determine the number of photons that illuminated each pixel. Tables I and II show the photometric parameters.

Table I. Photometric values for $460 \mathrm{~nm}$.

\begin{tabular}{cccc}
\hline \hline $\begin{array}{c}\text { RS-5 setting } \\
\left(\mu \mathrm{W} / \mathrm{cm}^{2}\right)\end{array}$ & $\begin{array}{c}\text { Photodiode Signal } \\
(\mathrm{nA})\end{array}$ & $\begin{array}{c}\text { Irradiance } \\
(\mathrm{nW} / \mathrm{cm} 2)\end{array}$ & Photons/pixel \\
\hline 100 & 25.24 & 100.97 & 109102 \\
70 & 17.78 & 71.11 & 76836 \\
50 & 12.75 & 51.00 & 55108 \\
20 & 5.14 & 20.55 & 22208 \\
10 & 2.57 & 10.29 & 11117 \\
5 & 1.29 & 5.15 & 5554 \\
\hline \hline
\end{tabular}

Table II. Photometric values for 530nm.

\begin{tabular}{cccc}
\hline \hline $\begin{array}{c}\text { RS-5 setting } \\
\left(\mu \mathrm{W} / \mathrm{cm}^{2}\right)\end{array}$ & $\begin{array}{c}\text { Photodiode Signal } \\
(\mathrm{nA})\end{array}$ & $\begin{array}{c}\text { Irradiance } \\
(\mathrm{nW} / \mathrm{cm} 2)\end{array}$ & Photons/pixel \\
\hline 100 & 15.05 & 100.34 & 94103 \\
70 & 10.60 & 70.63 & 66243 \\
50 & 7.60 & 50.67 & 47517 \\
20 & 3.06 & 20.42 & 19151 \\
10 & 1.54 & 10.26 & 9622 \\
5 & 0.77 & 5.13 & 4814 \\
\hline \hline
\end{tabular}


Next, measure the camera's bias and read noise. The two bias images were averaged together. The average signal from a $50 \times 50$ pixel sub-array in the camera's overscan region of the image is the camera's bias (or offset). The output circuitry is read out past the active pixel area. This area called the overscan region provides the noise contribution of the readout electronics. The standard deviation of this sub-array is the camera's read noise $\sigma_{\mathrm{RDN}}$.

At each illumination level the average signal, standard deviation were measured, and the gain constant were calculated for a 50 x 50 pixel sub-array region near the center for each of the flat-field images. The bias was subtracted to determine the true signal $\mathrm{S}_{\mathrm{DN}}$ for each illumination level.

A gain constant was calculated for each illumination level using equation 2. The standard deviation, $\sigma_{\text {SDN }}$ was calculated on the image after subtracting the first image from the second, to eliminate fixed pattern noise. The subtraction increased the noise variance by a power of two; this is why there is a two in the denominator. The camera gain provides the conversion coefficient used to calculate the number of electrons per analog to digital converter number. The conversion factor is $\mathrm{e}^{\mathrm{e} / \mathrm{DN}}$ (electrons per digital count) used to convert digital number or counts to electrons.

$$
k=\frac{S_{D N}}{\left(\frac{\sigma_{S D N}^{2}}{2}\right)-\sigma_{R D N}^{2}}
$$

The calculated quantum efficiency was $34.4 \%$ at $460 \mathrm{~nm}$ and $56.9 \%$ at $530 \mathrm{~nm}$. A Kodak 16801 CCD without the SITO processing had $14 \%$ at $460 \mathrm{~nm}$ and $35.1 \%$ at $530 \mathrm{~nm}$.

We used a classical photon transfer method to determine full well capacity based on Fig. 4. ${ }^{9}$ The $690 \mathrm{kHz}$ data falls off sooner in both the photon transfer curve and responsivity curve 
shown in Fig. 4 due to the higher sensitivity in camera gain compared to the $1000 \mathrm{kHz}$ readout rate. The higher sensitivity results in the analog to digital converter saturating for a lower number of electrons. Table III compares our results and the vendor results for Series 800 and Series 1000 cameras. The full well capacity is not calculated at the lower readout rate with its higher gain sensitivity because the 16-bit analog to digital converter saturates before the pixel full well capacity is reached.

The resolution measurements showed a CTF (Contrast Transfer Function) of 53\% at $32 \mathrm{lp} / \mathrm{mm}$ and $44 \%$ at $36 \mathrm{lp} / \mathrm{mm}$. The nominal $50 \% \mathrm{CTF}$ is $33.5 \mathrm{lp} / \mathrm{mm}$.

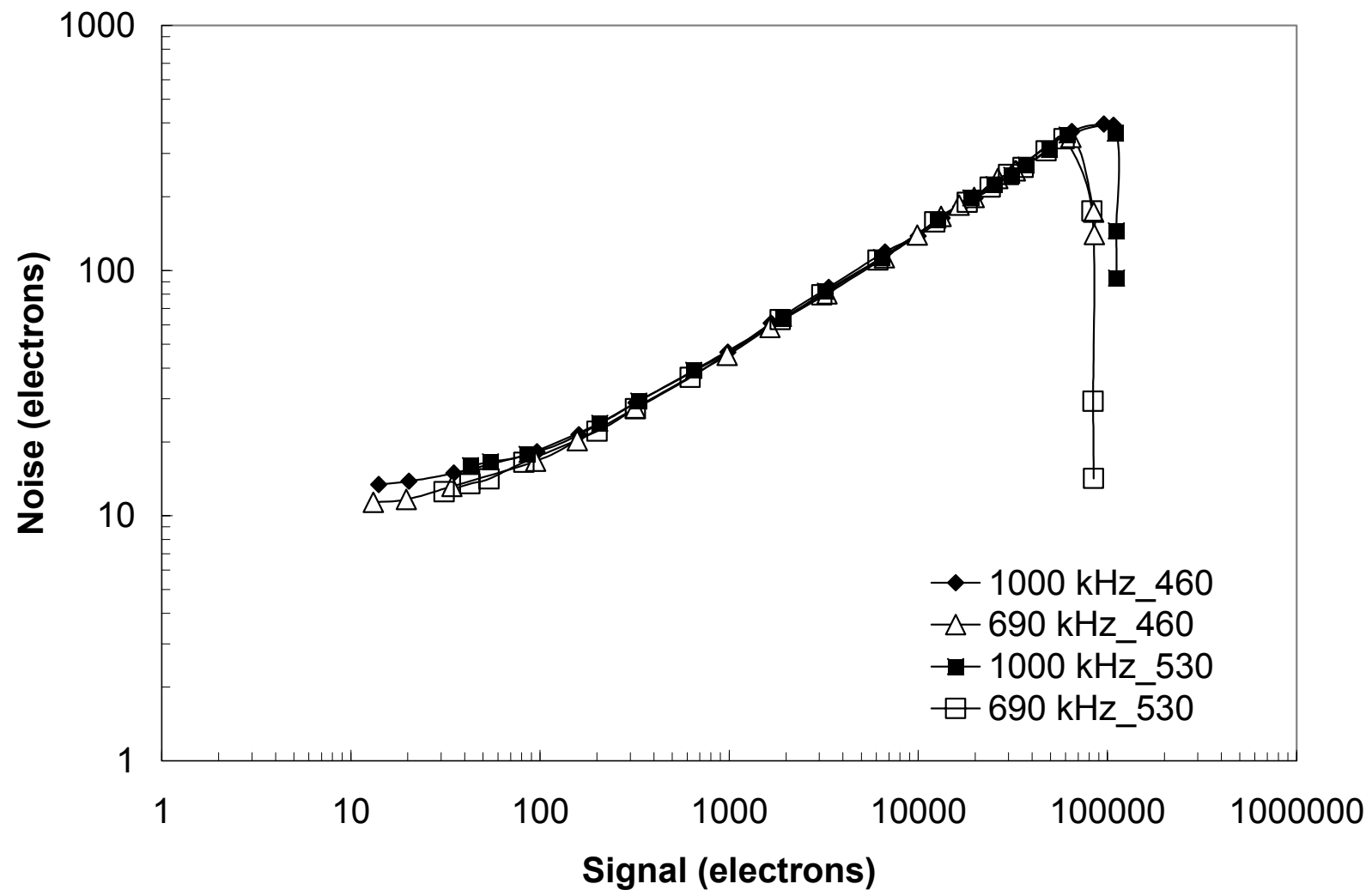

FIG. 4. Photon transfer curve 


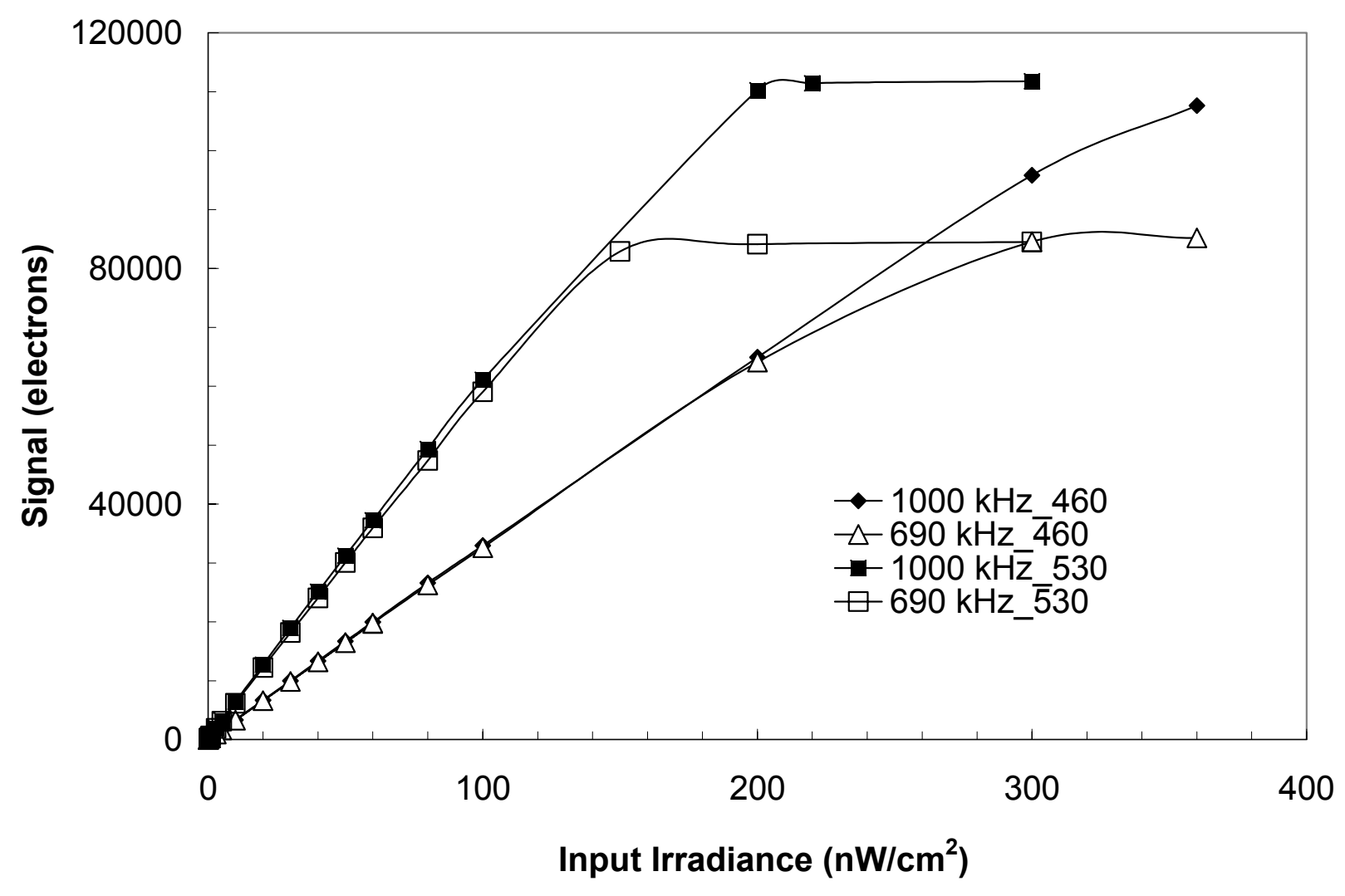

FIG. 5. Responsivity plot for the camera.

Table III. Camera dynamic range.

\begin{tabular}{|c|c|c|c|c|c|}
\hline $\begin{array}{c}\text { Camera } \\
\text { (model_sn) }\end{array}$ & $\begin{array}{l}\text { Readout Rate } \\
(\mathrm{kHz})\end{array}$ & $\begin{array}{c}\text { Camera Gain } \\
\text { (e-/DN) }\end{array}$ & $\begin{array}{c}\text { Read Noise } \\
(\mathrm{e}-)\end{array}$ & $\begin{array}{c}\text { Full Well } \\
(\mathrm{e}-)\end{array}$ & "Dynamic Range \\
\hline $\begin{array}{l}1000{ }_{1} 102^{\mathrm{a}} \\
1000 \_102\end{array}$ & $\begin{array}{r}690 \\
1000\end{array}$ & $\begin{array}{l}1.33 \\
2.64\end{array}$ & $\begin{array}{l}6.9 \\
8.8\end{array}$ & $\begin{array}{r}\text { NA } \\
103604\end{array}$ & $\begin{array}{r}\text { NA } \\
11773\end{array}$ \\
\hline $\begin{array}{l}1000 \_102^{b} \\
1000 \_102\end{array}$ & $\begin{array}{r}690 \\
1000\end{array}$ & $\begin{array}{l}1.39 \\
2.72\end{array}$ & $\begin{array}{l}7.3 \\
9.3\end{array}$ & $\begin{array}{r}\text { NA } \\
106000\end{array}$ & $\begin{array}{r}\text { NA } \\
11398\end{array}$ \\
\hline $\begin{array}{l}800-118^{c} \\
800118\end{array}$ & $\begin{array}{r}333 \\
1000 \\
\end{array}$ & $\begin{array}{l}0.43 \\
2.34\end{array}$ & $\begin{array}{r}7.7 \\
10.3 \\
\end{array}$ & $\begin{array}{r}\text { NA } \\
40000\end{array}$ & $\begin{array}{r}\text { NA } \\
3883\end{array}$ \\
\hline
\end{tabular}

${ }^{a}$ Full well was not measured at the lower readout rate.

${ }^{\mathrm{b}}$ All values below this on the chart are from Spectral Instruments specification sheet.

${ }^{\circ}$ Camera CCD was not Single Indium Tin Oxide design 


\section{CONCLUSION}

The Series 1000 camera system combines the need for a diagnostic controller and CCD camera into one unit resulting in a fully networked diagnostic. Measurements show the camera met or exceeded image specifications. In addition, the camera has the following advantages over the Series 800: better water cooling, vacuum enclosed CCD with monitor, network addressable, compatible with NIF triggers, and reduced size compared to the Series 800 . The camera and PC104+ controller are designed into the NIF GXD and NIF Dante diagnostics.

\section{ACKNOWLEDGEMENTS}

This work was performed under the auspices of the U.S. Department of Energy by University of California Lawrence Livermore National Laboratory under contract No. W-7405Eng-48.

${ }^{1}$ A. D. Conder, J. Dunn, B. K. F. Young, Rev. Sci. Instrum. 66, 709 (1995)

${ }^{2}$ L. M. Logory et al., Rev. Sci. Instrum. 69, 4054 (1998)

${ }^{3}$ R. E. Turner et al., Rev. Sci. Instrum. 72, 606 (2001)

${ }^{4}$ Spectral Instruments, Inc., Tucson, Az.

5“Requirements and Recommendations for Target Diagnostic Development," Lawrence Livermore National Laboratory, UCRL-MI-1333959

${ }^{6}$ PC104 Plus Specification Version 2.0, PC104 Embedded Consortium San Francisco, CA, Nov 2003 
${ }^{7}$ J. A. Oertel et al., Rev. Sci. Instrum. (these proceedings).

${ }^{8}$ E. L. Dewald et al., Rev. Sci. Instrum (these proceedings).

${ }^{9}$ J.R. Janesick, Scientific Charge-Coupled Devices, (SPIE Press, 2001), p. 101-105. 